\title{
Introduction to the Live Streaming Services Minitrack
}

\author{
Kaja J. Fietkiewicz \\ Dept. of Information Science \\ Heinrich Heine University Düsseldorf, Germany \\ kaja.fietkiewicz@hhu.de
}

\author{
Franziska Zimmer \\ Dept. of Information Science \\ Heinrich Heine University Düsseldorf, Germany \\ franziska.zimmer@hhu.de
}

Live videos are becoming more and more popular, either in form of standalone live streaming platforms (e.g., Periscope, Twitch or YouNow) or as live-video features embedded in other services (e.g., on Facebook or Instagram) [1]. With the emerging streaming services, information production and information consumption behavior substantially changed. The traditional usage patterns of watching TV evolved from the "lean-back" media usage to a space- and timeindependent consumption and, more importantly, to production and participation behavior [2;4].

What else makes the live streaming services so special? Unlike on many other social media, the interuser communication on live streaming platforms occurs synchronously, since the streamers and the viewers communicate in real-time with no time delay [4]. This in turn leads to a much differentiated social interaction and user engagement [1]. When we compare live streaming to traditional mass media, the viewers' motivation has a stronger social and community basis $[1 ; 3 ; 5]$.

One of the most popular and successful (in terms of hours of streamed videos as well as money made) platforms within the live streaming domain are the ones specializing in gaming (or esports), e.g. Twitch or LetsPlay (YouTube). Gaming video content is increasing in popularity, with people watching broadcasters play or review video games. But could this behavior influence the viewers, potentially even making them refrain from buying or playing games as they already watched them being played by someone else?

According to the findings by Törhönen, Sjöblom, Vahlo, and Hamari [6] the gaming industry should not worry about that. In their study, Törhönen et al. [6] focus on game related purchasing behavior and video game playing time in relation to the consumption of three popular forms of game content: let's plays, game reviews as well as electronic sports (esports). Let's play videos are a combination of gameplay videos and commentary by the player. This type of content focusses on the broadcaster and the relationship with the viewers, not necessarily the game itself. Game reviews focus on the game, as they provide a structured and analytical point of view. Esports events are competitive in nature, where players compete in tournaments. To gather insight into this user-centered study, an online survey was conducted and an analytical model applied. The results indicate that people who watch esports and review videos are more inclined to make game related purchases, whereas let's plays video content does not seem to influence this behavior. The aspect of playing video games is positively associated with all three types of video game content. Hence, the study gives new insights into the supporting role of live streaming for the gaming or esports industry.

\section{References}

[1] K.J. Fietkiewicz, "Guest editorial preface: Special issue on live videos in social media", International Journal of Interactive Communication Systems and Technologies, 9(2), 2019, pp. vi-viii.

[2] K.J. Fietkiewicz and W.G. Stock, "Introduction to the live streaming services minitrack", Proceedings of the 52nd Hawaii International Conference on System Sciences (pp. 2536-2537). Honolulu, HI: HICSS (ScholarSpace), 2019.

[3] Z. Hilvert-Bruce, J.T. Neil, M. Sjöblom, and J. Hamari, "Social motivations of live-streaming viewer engagement on Twitch", Computers in Human Behavior, 84, 2018. pp. 5867.

[4] K. Scheibe, K.J Fietkiewicz, and W.G. Stock, "Information behavior on social live streaming services", Journal of Information Science Theory and Practice, 4(2), 2016, pp. 6-20.

[5] F. Zimmer and K. Scheibe, "What drives streamers? Users' characteristics and motivations on social lives streaming services", in Proceedings of the 52nd Hawaii International Conference on System Sciences HICSS (ScholarSpace), 2019.

[6] M. Törhönen, M. Sjöblom, J. Vahlo, and J. Hamari, "View, play and pay? - The relationship between consumption of gaming video content and video game playing and buying", in Proceedings of the 53rd Hawaii International Conference on System Sciences HICSS (ScholarSpace), 2020. 